\title{
Comparison of different staging methods for COPD in predicting outcomes
}

\author{
Tang-Hsiu Huang ${ }^{1}$, Tzuen-Ren Hsiue ${ }^{1}$, Sheng-Hsiang Lin ${ }^{2,3,4}$, Xin-Ming Liao ${ }^{1}$, \\ Po-Lan Su${ }^{1}$ and Chiung-Zuei Chen ${ }^{1}$
}

Affiliations: ${ }^{1}$ Division of Chest Medicine, Dept of Internal Medicine, National Cheng Kung University, College of Medicine and Hospital, Tainan, Taiwan. ${ }^{2}$ Institute of Clinical Medicine, College of Medicine, National Cheng Kung University, Tainan, Taiwan. ${ }^{3}$ Dept of Public Health, College of Medicine, National Cheng Kung University, Tainan, Taiwan. ${ }^{4}$ Biostatistics Consulting Center, National Cheng Kung University Hospital, Tainan, Taiwan.

Correspondence: Chiung-Zuei Chen, Division of Chest Medicine, Dept of Internal Medicine, National Cheng Kung University Hospital, No 138, Sheng-Li Road, Tainan 704, Taiwan. E-mail: tangomycin0713dagmail.com

@ERSpublications

Reference-independent methods for staging COPD performed better than the GOLD criteria in predicting outcomes http://ow.ly/W95F30iiMKO

Cite this article as: Huang T-H, Hsiue T-R, Lin S-H, et al. Comparison of different staging methods for COPD in predicting outcomes. Eur Respir J 2018; 51: 1700577 [https://doi.org/10.1183/13993003.005772017].

ABSTRACT Chronic obstructive pulmonary disease (COPD) is commonly staged according to the percentage of predicted forced expiratory volume in $1 \mathrm{~s}$ (FEV1 \% pred), but other methods have been proposed. In this study we compared the performance of seven staging methods in predicting outcomes.

We retrospectively studied 296 COPD outpatients. For each patient the disease severity was staged by separately applying the following methods: the criteria proposed by the Global Initiative for Chronic Obstructive Lung Disease (GOLD), quartiles of FEV1 \% pred and $z$-score of FEV1, quartiles and specified cut-off points of the ratio of FEV1 over height squared $\left(\left(\mathrm{FEV} 1 \cdot \mathrm{Ht}^{-2}\right)_{\mathrm{A}}\right.$ and $\left(\mathrm{FEV} 1 \cdot \mathrm{Ht}^{-2}\right)_{\mathrm{B}}$, respectively), and quartiles of the ratio of $\mathrm{FEV} 1$ over height cubed $\left(\mathrm{FEV}_{1} \cdot \mathrm{Ht}^{-3}\right)$ and of $\mathrm{FEV} 1$ quotient (FEV1Q). We evaluated the performance of these methods in predicting the risks of severe acute exacerbation and all-cause mortality.

Overall, staging based on the reference-independent FEV1Q performed best in predicting the risks of severe acute exacerbation (including frequent exacerbation) and mortality, followed by $\left(\mathrm{FEV} 1 \cdot \mathrm{Ht}^{-2}\right)_{\mathrm{B}}$. The performance of staging methods could also be influenced by the choice of cut-off values. Future work using large and ethnically diverse populations to refine and validate the cut-off values would enhance the prediction of outcomes.

This article has supplementary material available from erj.ersjournals.com

Received: Dec 142016 | Accepted after revision: Jan 312018

Support statement: This study was supported by the grant NCKUH-10508003 from National Cheng Kung University Hospital. The sponsor had no role in the design, methods, subject recruitment, data collections, data analysis or preparation of the paper. Funding information for this article has been deposited with the Crossref Funder Registry.

Conflict of interest: None declared.

Copyright @ERS 2018 


\section{Introduction}

Chronic obstructive pulmonary disease (COPD) is a major cause of morbidity and mortality worldwide [1]. Accurate staging of COPD is important for determining treatment strategy and prognosis. Common staging based on the percentage of predicted forced expiratory volume in $1 \mathrm{~s}$ (FEV1 \% pred), as proposed by the Global Initiative for Chronic Obstructive Lung Disease (GOLD), has been criticised for its susceptibility to the influence of patient age, height, sex and race [2-4]. Alternative expressions of forced expiratory volume in $1 \mathrm{~s}(\mathrm{FEV} 1)$ for staging COPD have been proposed. Staging based on $\mathrm{z}$-scores of FEV 1 potentially avoids the confounding effect of inter-personal physiological variations [4-6]. Other alternative staging methods are independent of reference values, such as the ratios of FEV1 over height squared $\left(\mathrm{FEV} 1 \cdot \mathrm{Ht}^{-2}\right)$ and over height cubed $\left(\mathrm{FEV} 1 \cdot \mathrm{Ht}^{-3}\right)$, and the ratio of $\mathrm{FEV} 1$ over the sex-specific Miller values (FEV1 quotient, or FEV1Q) [7-10]. Most studies evaluating these alternative methods were done before the Global Lung Function Initiative (GLI) issued their multi-ethnic reference equations [3]. Studies by Turkeshi et al. [11] and Hegendörfer et al. [12] applied the GLI reference equations while comparing the prognostic performance of different expressions of FEV1. These studies, however, were not performed specifically on patients with COPD $[11,12]$. In the present study, with the application of the GLI reference equations and working with a cohort of patients with COPD, we aimed to evaluate the performance of staging based on different expressions of FEV1 in predicting the risk of two important clinical outcomes: severe acute exacerbation (SAE) and all-cause mortality.

\section{Methods \\ Study design and population}

This was a retrospective study using delinked clinical data from a database that was established in our previous study [13]. All patients were aged between 40 and 95 years old, had received a diagnosis of COPD by board-certified pulmonologists at the tertiary medical centre National Cheng Kung University Hospital, Taiwan, between January 2006 and December 2012, and had been followed for at least 1 year or until death. For the analysis of all-cause mortality, only those patients with complete longitudinal data at the final censoring date of the study (April 30, 2015) were included. The diagnosis of COPD required that the ratio of FEV1 to forced vital capacity (FVC) be lower than the fifth percentile value (lower-limit-of-normal) of the population $[1,14,15]$. Post-bronchodilator values were used if available. Patients with asthma or advanced-stage malignancy of any organ, patients lost to follow-up, and patients with incomplete or questionable data were excluded from the study. Relevant data (including sex, age, height, body mass index (BMI), cigarette smoking history, Charlson comorbidity index, frequency of SAE during the year before and the first 3 years after study enrolment, survival status and spirometric measurements) were obtained from medical records and delinked. SAE was defined, according to relevant guidelines, as an acute event characterised by the worsening of respiratory symptoms that were beyond daily variation and required hospitalisation [1, 16]. Experienced and board-certified pulmonary technicians at our hospital performed all pulmonary function tests according to standard protocols established by the American Thoracic Society [17]. All patients were in a stable condition when they underwent pulmonary function tests. The test that was closest in date to study enrolment was considered the baseline test. For each patient, we calculated five expressions of FEV1 (FEV1 \% pred, z-score, $\mathrm{FEV} 1 \cdot \mathrm{Ht}^{-2}, \mathrm{FEV}_{1} \cdot \mathrm{Ht}^{-3}$ and $\left.\mathrm{FEV} 1 \mathrm{Q}\right)$. We used the GLI specialised software and reference equations for South East Asians to convert the measured FEV1 to $\mathrm{FEV}_{1} \%$ pred and z-scores [3]. When calculating FEV1Q, we used the Miller values (i.e. $0.5 \mathrm{~L}$ for males and $0.4 \mathrm{~L}$ for females) [9]. This study was approved by the Institutional Review Board of the National Cheng Kung University Hospital (A-ER-104-366).

\section{COPD severity staging}

For each patient, the severity of COPD was staged into four stages (stage 1-4 in order of increasing severity) using the different expressions of FEV1. Cut-off values for staging based on FEV1 \% pred were those proposed by GOLD (i.e. $80 \%, 50 \%$ and 30\%) and quartiles of $\mathrm{FEV}_{1} \%$ pred. Quartiles were also applied as cut-off values for staging based on $\mathrm{z}$-scores, FEV1 $\cdot \mathrm{Ht}^{-3}$ and $\mathrm{FEV} 1 \mathrm{Q}[9,11,12]$. For staging based on FEV1 $\cdot \mathrm{Ht}^{-2}$, we used two distinct sets of cut-off values: for $\left(\mathrm{FEV} 1 \cdot \mathrm{Ht}^{-2}\right)_{\mathrm{A}}$ we used quartiles, whereas for $\left(\mathrm{FEV} 1 \cdot \mathrm{Ht}^{-2}\right)_{\mathrm{B}}$ we used the cut-off values proposed by Miller et al. [7] (i.e. 0.3, 0.4 and 0.5). In total, we evaluated seven staging methods.

\section{Statistical analysis}

Categorical data are presented as counts and percentages, while continuous data (mostly not normally distributed as assessed by the Shapiro-Wilk test) are presented as medians and interquartile ranges (IQR). Variables between groups were compared via Mann-Whitney U test or Pearson's Chi-squared test of homogeneity as appropriate. Single- and multivariate logistic regression was carried out to determine the performance of each staging method in predicting the risk of having at least one SAE at 1 year, the risk of frequent $(\geqslant 2) \mathrm{SAE}$ at 1 year, and the risk of having SAE every year at 2 years. No co-linearity or 
interaction among all the candidate variates was found. Adjustment was made for age, BMI, Charlson comorbidity index, smoking status and history of SAE in the year preceding enrolment. Kaplan-Meier curves were plotted and log-rank tests performed to compare differences in the survival of patients at different stages based on each staging method. Single- and multivariate Cox proportional hazard regression analyses (adjusting for covariates such as age, BMI, Charlson comorbidity index, smoking status and history of SAE in the preceding year) were carried out to assess the performance of each staging method in predicting mortality risk. No violation of the proportional hazard assumption was detected. A p-value $<0.05$ was considered to indicate statistical significance; all tests were two-tailed. Statistical analysis was performed with the statistical packages SPSS (Version 22, SPSS, Chicago, IL, USA), R (Version 3.3.2) and MedCal (Version 16.8.4, MedCal Software, Ostend, Belgium).

\section{Results}

We screened the data of 667 outpatients, and identified 296 patients who met the inclusion criteria and were therefore enrolled into the study (figure 1). Table 1 shows the baseline characteristics of the cohort. Most participants were male (94\%), and either current $(60 \%)$ or former $(30 \%)$ smokers. Patients were followed for a median duration of 57.9 months (IQR 49.8 months, range 14 days to 9.5 years). Pre-bronchodilator spirometric data were used for 56 patients (19\%) owing to a lack of bronchodilator tests. We determined that 72 patients (24\%) died during follow-up, and the median duration from enrolment to death was 43.5 months (IQR 39.9 months, range 14 days to 8.5 years). There were complete longitudinal data up to the final censoring date for 189 patients $(64 \%)$, which were thus included for the analysis of all-cause mortality. There was no significant difference in baseline characteristics between those included and those excluded from the mortality analysis, except for a lower Charlson comorbidity index (median 1, IQR 1) and a shorter duration of follow-up (median 37.6 months, IQR 26.4 months) in those excluded (table 1).

The distributions of the measured FEV1, FEV1 \% pred, FEV1 $\cdot \mathrm{Ht}^{-2}, \mathrm{FEV}_{1} \cdot \mathrm{Ht}^{-3}$ and FEV1Q of our patients all exhibit positive skewness, while z-scores of FEV1 are normally distributed (figure S1a-f). Although we applied the Miller values for deriving FEV1Q for our patients, we also calculated the sex-specific first-percentile value of FEV1 for our study cohort, which was 0.51 for males and 0.52 for females. Our male-specific first-percentile value highly agrees with the Miller value for males (0.5), and the difference between our female-specific first-percentile value and the Miller value for females (0.4) is likely due to the small number of female patients (17 of $296(6 \%))$ in our cohort [9].

Table 2 displays the distribution of patients with a specific outcome across the stages based on different staging methods. We found that 48 patients (16\%) had at least one SAE at 1 year of follow-up. Of these, 22 patients $(7 \%)$ had two or more episodes of SAE. Additionally, 23 patients (8\%) had SAE every year at 2 years. Staging based on $\left(\mathrm{FEV} 1 \cdot \mathrm{Ht}^{-2}\right)_{\mathrm{A}},\left(\mathrm{FEV} 1 \cdot \mathrm{Ht}^{-2}\right)_{\mathrm{B}}, \mathrm{FEV} \cdot \mathrm{Ht}^{-3}$ and $\mathrm{FEV} 1 \mathrm{Q}$ stratified the distribution of

FIGURE 1 Flow chart of inclusion and exclusion for this study. COPD: chronic obstructive pulmonary disease; GLI: Global Lung Function Initiative.

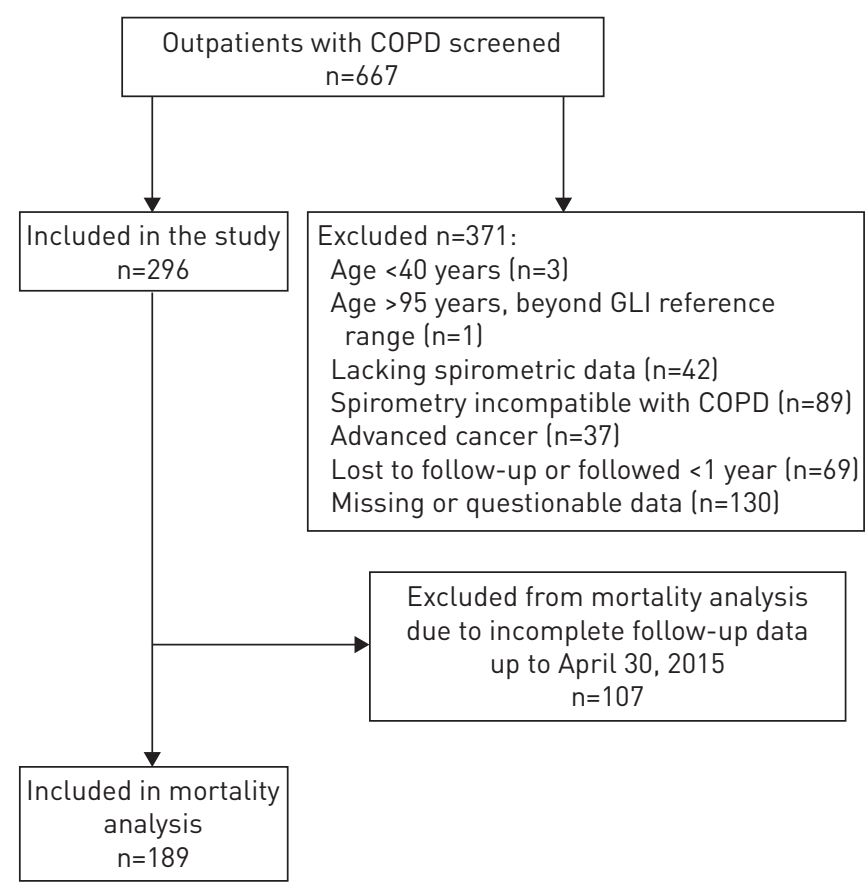


TABLE 1 Baseline characteristics of the study cohort

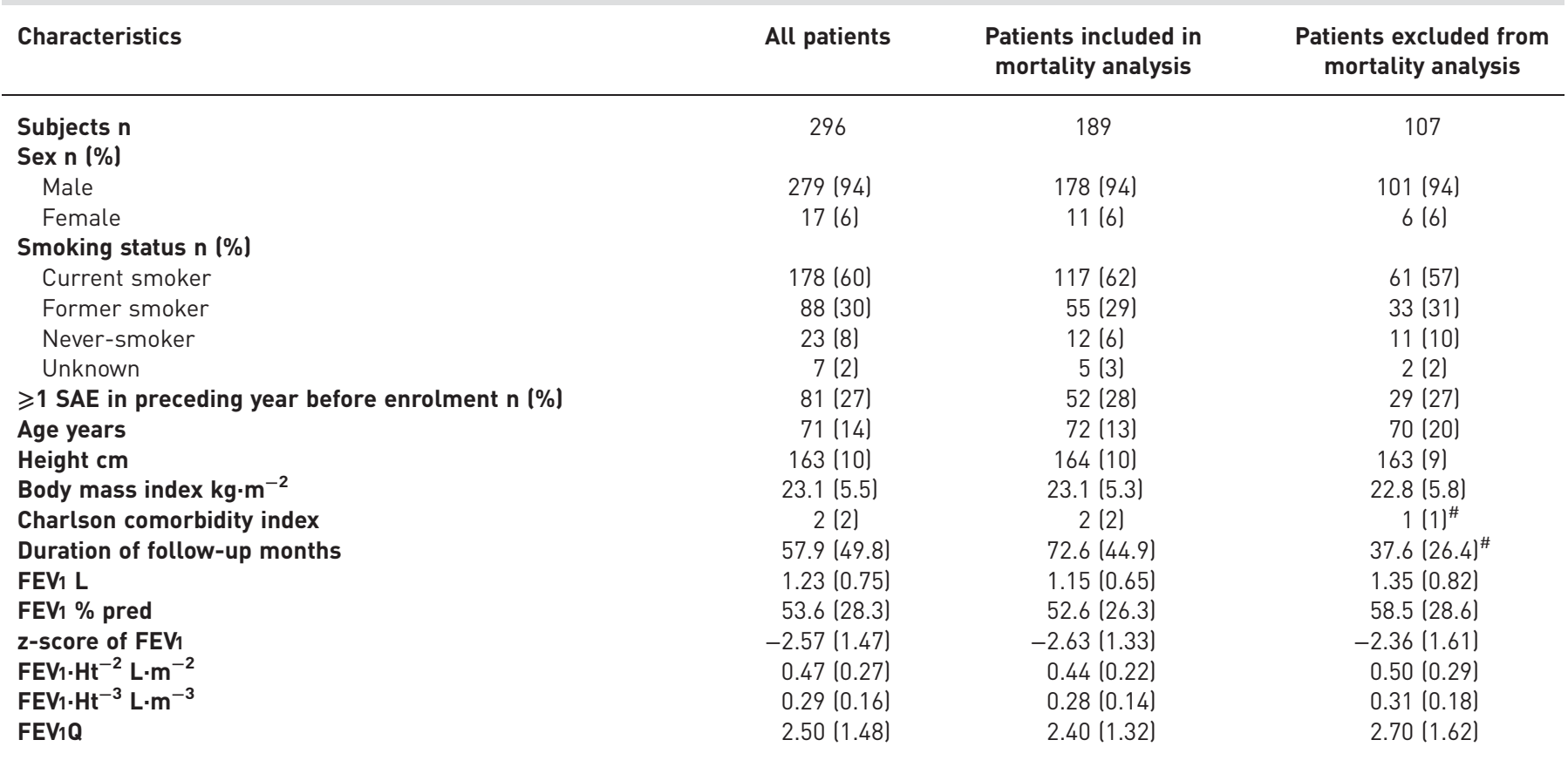

Data are presented as median (interquartile range), unless otherwise stated. SAE: severe acute exacerbation; FEV1: forced expiratory volume in $1 \mathrm{~s} ; \mathrm{FEV} 1 \%$ pred: percentage of predicted $\mathrm{FEV} 1 ; \mathrm{FEV}_{1} \cdot \mathrm{Ht}^{-2}$ : $\mathrm{FEV} 1$ over height squared; $\mathrm{FEV} 1 \cdot \mathrm{Ht}^{-3}$ : FEV1 over height cubed; $\mathrm{FEV} \mathrm{V}_{1} \mathrm{Q}$ : $\mathrm{FEV} 1$ quotient. ${ }^{\#}$ : $p<0.005$ for comparison with the same characteristic of patients included in the mortality analysis.

patients with SAE-related outcomes well, with advancing stages having elevating percentages of patients with SAE-related outcomes. In contrast, staging based on the GOLD criteria, FEV $1 \%$ pred (quartiles) and z-scores did not stratify well. For mortality, staging based on the GOLD criteria, FEV1 \% pred (quartiles), $\left(\mathrm{FEV}_{1} \cdot \mathrm{Ht}^{-2}\right)_{\mathrm{B}}$ and $\mathrm{FEV} 1 \mathrm{Q}$ yielded progressively increasing mortality rates across ascending stages. Staging based on z-scores, $\left(\mathrm{FEV} 1 \cdot \mathrm{Ht}^{-2}\right)_{\mathrm{A}}$ and $\mathrm{FEV} 1 \cdot \mathrm{Ht}^{-3}$ performed worse in this regard (table 2).

Single- and multivariate logistic regression assessing the risk of SAE revealed that staging methods that were independent of predicted reference values performed better than reference-dependent methods. Staging based on FEV1Q and $\left(\mathrm{FEV}_{1} \cdot \mathrm{Ht}^{-2}\right)_{\mathrm{A}}$ consistently discriminated the risk of SAE well, including the risk of $\geqslant 1$ SAE at 1 year as shown in table 3 , and the risk of frequent SAE at 1 year and having SAE every year at 2 years as shown in table 4 . Advancing stages had progressively increasing crude and adjusted odds ratios. Staging based on $\left(\mathrm{FEV} 1 \cdot \mathrm{Ht}^{-2}\right)_{\mathrm{B}}$ and $\mathrm{FEV} 1 \cdot \mathrm{Ht}^{-3}$ also showed an overall incremental trend of the risk of SAE across the ascending stages. However, for these two methods, the crude and adjusted odds ratios for $\geqslant 1$ SAE at 1 year were slightly lower for stage 4 than for stage 3 . For staging based on $\left(\mathrm{FEV}_{1} \cdot \mathrm{Ht}^{-2}\right)_{\mathrm{B}}$, the adjusted odds ratio for frequent SAE at 1 year was also very slightly lower for stage 4 than for stage 3. In contrast, all three reference-dependent staging methods (i.e. GOLD, FEV1 \% pred (quartiles) and $\mathrm{z}$-scores) performed unsatisfactorily in stratifying the risk of SAE (tables 3 and 4).

The Kaplan-Meier survival curves for staging based on $\mathrm{FEV} 1 \%$ pred (quartiles), $\left(\mathrm{FEV} \cdot \mathrm{Ht}^{-2}\right)_{\mathrm{B}}$ and FEV $1 \mathrm{Q}$ discriminated the survival differences of the patients in different stages. However, the survival curves for staging based on $\mathrm{z}$-scores, $\left(\mathrm{FEV} 1 \cdot \mathrm{Ht}^{-2}\right)_{\mathrm{A}}$ and $\mathrm{FEV} \cdot \mathrm{Ht}^{-3}$ showed early crossovers between stages 3 and 4 . The survival curves for GOLD-based stages separated well initially but then exhibited late-phase crossovers between stages 1 and 2 and between stages 3 and 4, which were likely caused by the low numbers of remaining subjects at risk near the end of follow-up (figure $2 \mathrm{a}-\mathrm{g}$ ).

Single- and multivariate Cox regression analysis revealed that, consistent with the distribution of mortality rates as displayed in table 2, staging based on $\mathrm{FEV} 1 \%$ pred (quartiles), $\mathrm{FEV} 1 \mathrm{Q}$ and $\left(\mathrm{FEV}_{1} \cdot \mathrm{Ht}^{-2}\right)_{\mathrm{B}}$ in particular stratified the mortality risk well, with advancing stages exhibiting progressively increasing crude and adjusted hazard ratios. For the GOLD stages, the crude and adjusted hazard ratios showed a similarly incremental trend, but mostly without reaching statistical significance. Stages based on Z-scores exhibited progressively increasing mortality risk only in the multivariate Cox regression model. Staging based on $\left(\mathrm{FEV} 1 \cdot \mathrm{Ht}^{-2}\right)_{\mathrm{A}}$ and $\mathrm{FEV} 1 \cdot \mathrm{Ht}^{-3}$ performed unsatisfactorily in predicting the different mortality risk across the stages (table 5). 
TABLE 2 Distribution of patient numbers and frequencies of adverse outcomes across different stages based on the seven staging methods

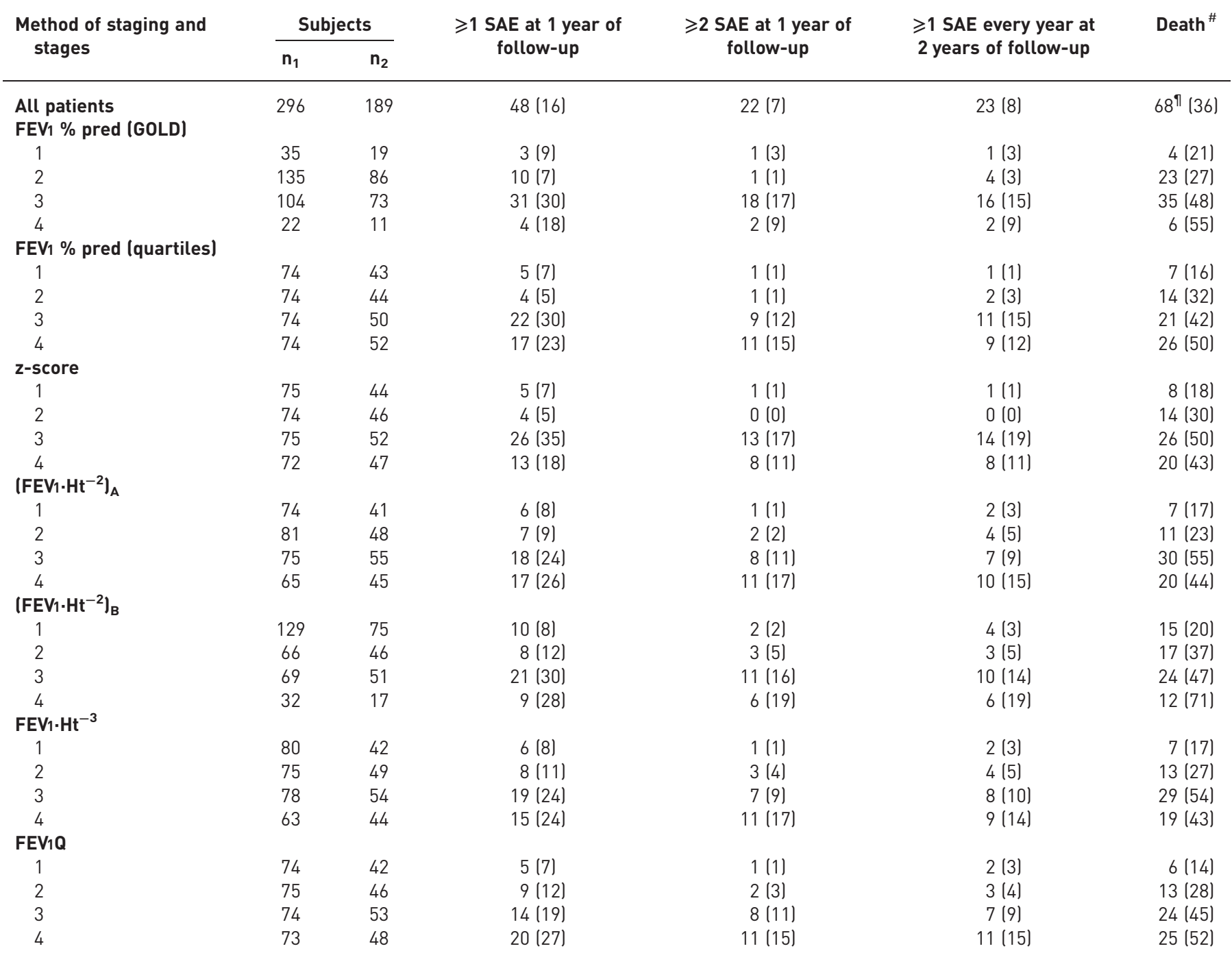

Data are presented as $n\left(\%\right.$ of $\left.n_{1}\right)$, unless otherwise stated. $n_{1}$ : number of patients included in SAE-related analysis; $n_{2}$ : number of patients included in mortality analysis; SAE: severe acute exacerbation; FEV1: forced expiratory volume in $1 \mathrm{~s}$; FEV $1 \%$ pred: percentage of predicted FEV1; GOLD: Global Initiative for Chronic Obstructive Lung Disease; FEV1 $\cdot \mathrm{Ht}^{-2}$ : FEV1 over height squared; FEV1. $\mathrm{Ht}^{-3}$ : FEV1 over height cubed; FEV1Q: FEV1 quotient. "\#: numbers indicating the percentages of $n_{2}$ for each stage; ${ }^{\text {ๆ: }}$ four of the total 72 deaths were excluded from the mortality analysis owing to incomplete data.

Considering the relatively small size of our cohort and the skewed distribution of the major variables, we further applied bootstrapping (with 5000 random samplings with replacement, using SAS version 9.4 (SAS Institute, Cary, NC, USA)) to all the logistic and Cox regression analyses to enhance the accuracy of our statistical estimates. The bootstrapping-derived crude and adjusted odds ratios and hazard ratios, and the corresponding 95\% confidence intervals, generally reached statistical significance and agreed with the findings obtained from our original regression models (tables S1 and S2).

\section{Discussion}

In this study, we compared seven methods for staging the severity of COPD. We showed that staging based on FEV1Q accurately predicted survival and the risks of all the adverse outcomes studied. Staging based on $\left(\mathrm{FEV} 1 \cdot \mathrm{Ht}^{-2}\right)_{\mathrm{B}}$ also performed well in general, particularly in predicting mortality risk, although there was a slight inversion in the crude and adjusted odds ratios for $\geqslant 1$ SAE at 1 year and in the adjusted odds ratios for frequent SAE at 1 year between stages 3 and 4. A slight inversion in the bootstrappingderived adjusted hazard ratios for mortality was also noticed between stages 2 and 3. Staging based on 
TABLE 3 Single- and multivariate logistic regression assessing the risk of having at least one severe acute exacerbation at 1 year of follow-up

\begin{tabular}{|c|c|c|}
\hline Method of staging (cut-off values) & $\begin{array}{c}\text { Crude } O R \text { for } \geqslant 1 \text { SAE } \\
\text { at } 1 \text { year }(95 \% \mathrm{CI})\end{array}$ & $\begin{array}{c}\text { Adjusted } O \mathrm{R}^{\#} \text { for } \geqslant 1 \mathrm{~S} \\
\text { at } 1 \text { year }(95 \% \mathrm{CI})\end{array}$ \\
\hline \multicolumn{3}{|l|}{ FEV $1 \%$ pred (GOLD) } \\
\hline $1(\geqslant 80 \%)$ & 1 & 1 \\
\hline $2(\geqslant 50 \%$ and $<80 \%)$ & $0.85(0.22-3.28)$ & $0.91(0.21-4.06)$ \\
\hline $3(\geqslant 30 \%$ and $<50 \%)$ & $4.53(1.29-15.90)^{+}$ & $4.03(0.96-16.83)$ \\
\hline $4(<30 \%)$ & $2.37(0.48-11.79)$ & $2.05(0.33-12.55)$ \\
\hline \multicolumn{3}{|l|}{ FEV $1 \%$ pred (quartiles) } \\
\hline $1(\geqslant 69.3 \%)$ & 1 & 1 \\
\hline $2(\geqslant 53.6 \%$ and $<69.3 \%)$ & $0.79(0.20-3.06)$ & $0.67(0.16-2.77)$ \\
\hline $3(\geqslant 41.0 \%$ and $<53.6 \%)$ & $5.84(2.07-16.45)^{\S}$ & $4.89(1.61-14.81)^{+}$ \\
\hline $4[<41.0 \%)$ & $4.12(1.43-11.85)^{+}$ & $3.02(0.93-9.77)$ \\
\hline \multicolumn{3}{|l|}{ z-score (quartiles) } \\
\hline $1(\geqslant-1.70)$ & 1 & 1 \\
\hline $2(\geqslant-2.57$ and $<-1.70)$ & $0.80(0.21-3.10)$ & $0.67(0.16-2.77)$ \\
\hline $3(\geqslant-3.17$ and $<-2.57)$ & $7.43(2.67-20.69)^{\S}$ & $6.54(2.14-20.01)^{\S}$ \\
\hline $4(<-3.17)$ & $3.09(1.04-9.16)^{+}$ & $2.87(0.83-9.95)$ \\
\hline \multicolumn{3}{|l|}{ (FEV $\left.1 \cdot \mathrm{Ht}^{-2}\right)_{\mathrm{A}}$ (quartiles) } \\
\hline $1(\geqslant 0.63)$ & 1 & 1 \\
\hline $2(\geqslant 0.47$ and $<0.63)$ & $1.09(0.35-3.40)$ & $0.97(0.29-3.31)$ \\
\hline $3(\geqslant 0.36$ and $<0.47)$ & $3.63(1.35-9.76)^{+}$ & $2.79(0.94-8.31)$ \\
\hline $4(<0.36)$ & $4.07(1.50-11.08)^{+}$ & $2.85(0.93-8.70)$ \\
\hline \multicolumn{3}{|l|}{$\left(F E V_{1} \cdot \mathrm{Ht}^{-2}\right)_{B}{ }^{\Uparrow}$} \\
\hline $1(\geqslant 0.50)$ & 1 & 1 \\
\hline $2(\geqslant 0.40$ and $<0.50)$ & $1.64(0.62-4.38)$ & $1.38(0.49-3.89)$ \\
\hline $3(\geqslant 0.30$ and $<0.40)$ & $5.21(2.28-11.87)^{\S}$ & $4.34(1.78-10.61)^{\S}$ \\
\hline $4(<0.30)$ & $4.66(1.70-12.72)^{\S}$ & $3.37(1.10-10.35)^{+}$ \\
\hline \multicolumn{3}{|l|}{$\mathrm{FEV} 1 \cdot \mathrm{Ht}^{-3}$ (quartiles) } \\
\hline $1(\geqslant 0.38)$ & 1 & 1 \\
\hline $2(\geqslant 0.29$ and $<0.38)$ & $1.47(0.49-4.46)$ & $1.37(0.42-4.47)$ \\
\hline $3(\geqslant 0.22$ and $<0.29)$ & $3.97(1.49-10.58)^{+}$ & $3.36(1.15-9.82)^{+}$ \\
\hline $4(<0.22)$ & $3.85(1.40-10.63)^{+}$ & $2.70(0.88-8.25)$ \\
\hline \multicolumn{3}{|l|}{$F_{E V} Q Q$ (quartiles) } \\
\hline $1(\geqslant 3.38)$ & 1 & 1 \\
\hline $2(\geqslant 2.50$ and $<3.38)$ & $1.88(0.60-5.91)$ & $1.89(0.54-6.61)$ \\
\hline $3(\geqslant 1.90$ and $<2.50)$ & $3.22(1.10-9.46)^{+}$ & $2.66(0.80-8.88)$ \\
\hline $4(<1.90)$ & $5.21(1.84-14.78)^{\S}$ & $4.03(1.23-13.19)^{+}$ \\
\hline
\end{tabular}

SAE: severe acute exacerbation; FEV1: forced expiratory volume in $1 \mathrm{~s} ; \mathrm{FEV}_{1} \%$ pred: percentage of predicted FEV1; GOLD: Global Initiative for Chronic Obstructive Lung Disease; $F E V_{1} \cdot \mathrm{Ht}^{-2}$ : FEV 1 over height squared; $\mathrm{FEV}_{1} \cdot \mathrm{Ht}^{-3}$ : $\mathrm{FEV} 1$ over height cubed; $\mathrm{FEV}_{1} \mathrm{Q}$ : FEV1 quotient. ${ }^{\#}$ : adjustment was made for age, body mass index, Charlson comorbidity index, smoking status and history of SAE in the preceding year; " cut-off values $(0.3,0.4,0.5)$ were proposed in $[7]{ }^{+}: p<0.05 ;{ }^{\S}: p<0.005$.

$\left(\mathrm{FEV} 1 \cdot \mathrm{Ht}^{-2}\right)_{\mathrm{A}}$ and $\mathrm{FEV} 1 \cdot \mathrm{Ht}^{-3}$ discriminated the SAE-associated risks well, but performed unsatisfactorily in predicting the survival differences and mortality risk. The commonly applied GOLD criteria using GLI reference equations failed to discriminate all the SAE-associated risks, and predicted the mortality risk less well than FEV1Q and $\left(\mathrm{FEV} 1 \cdot \mathrm{Ht}^{-2}\right)_{\mathrm{B}}$. By using different cut-off values from the GOLD criteria, staging based on FEV1 \% pred (quartiles) better predicted the risks of mortality and of frequent SAE at 1 year, but still inadequately differentiated other SAE-associated risks. Staging based on GLI-derived z-scores performed well only in the multivariate Cox regression model for mortality after adjusting for confounders, but completely failed to predict all the SAE-associated risks.

The severity of COPD, as represented by the degree of impairment in FEV1, is associated with acute exacerbation [18-27] and mortality [28-34]. However, the best method and cut-off values for staging the severity of COPD remain to be identified. The commonly used GOLD criteria have been criticised for their liability to bias [2-4]. Pioneering works by MiLler and co-workers [7, 8] showed that staging based on reference-independent $\mathrm{FEV} 1 \cdot \mathrm{Ht}^{-2}$ and $\mathrm{FEV} 1 \cdot \mathrm{Ht}^{-3}$ correlated well with mortality. Later, MiLLER et al. [9] found that FEV1Q-based staging was an even better predictor of survival. The superiority of $\mathrm{FEV} 1 \mathrm{Q}$, and to a lesser extent $\mathrm{FEV} \cdot \mathrm{Ht}^{-3}$, over other expressions in staging COPD was further 
TABLE 4 Single- and multivariate logistic regression assessing the risks of having frequent severe acute exacerbation (SAE) at 1 year and having SAE every year at 2 years

\begin{tabular}{|c|c|c|c|c|}
\hline $\begin{array}{l}\text { Method of staging } \\
\text { (cut-off values) }\end{array}$ & $\begin{array}{l}\text { Crude } O R \text { for } \geqslant 2 \text { SAE } \\
\text { at } 1 \text { year }(95 \% \mathrm{CI})\end{array}$ & $\begin{array}{l}\text { Adjusted } O R^{\#} \text { for } \geqslant 2 \\
\text { SAE at } 1 \text { year }(95 \% \mathrm{CI})\end{array}$ & $\begin{array}{c}\text { Crude } O R \text { for } \geqslant 1 \text { SAE every } \\
\text { year at } 2 \text { years }(95 \% \mathrm{CI})\end{array}$ & $\begin{array}{r}\text { Adjusted } O R^{\#} \text { for } \geqslant 1 S A \\
\text { every year at } 2 \text { years } 195 \%\end{array}$ \\
\hline \multicolumn{5}{|l|}{ FEV $1 \%$ pred (GOLD) } \\
\hline $1(\geqslant 80 \%)$ & 1 & 1 & 1 & 1 \\
\hline $2(\geqslant 50 \%$ and $<80 \%)$ & $0.25(0.02-4.16)$ & $0.23(0.01-5.49)$ & $0.98(0.11-9.05)$ & $1.33(0.11-15.51)$ \\
\hline $3(\geqslant 30 \%$ and $<50 \%)$ & $7.12(0.91-55.41)$ & $4.39(0.34-56.46)$ & $5.85(0.74-46.07)$ & $7.65(0.75-78.06)$ \\
\hline $4(<30 \%)$ & $3.40(0.29-39.92)$ & $1.61(0.08-31.61)$ & $3.33(0.28-39.43)$ & $5.21(0.33-81.84)$ \\
\hline \multicolumn{5}{|l|}{ FEV $1 \%$ pred (quartiles) } \\
\hline $1(\geqslant 69.3 \%)$ & 1 & 1 & 1 & 1 \\
\hline $2(\geqslant 53.6 \%$ and $<69.3 \%)$ & $1.00(0.06-16.29)$ & $0.70(0.04-13.86)$ & $2.06(0.18-23.27)$ & 2.28 (0.19-27.98) \\
\hline $3(\geqslant 41.0 \%$ and $<53.6 \%)$ & $10.11(1.25-81.95)^{+}$ & $6.63(0.66-67.11)$ & $12.90(1.62-102.91)^{+}$ & $12.92(1.49-112.32)^{+}$ \\
\hline $4(<41.0 \%)$ & $12.75(1.60-101.48)^{+}$ & $6.82(0.64-72.22)$ & $10.03(1.24-81.50)^{+}$ & $11.68(1.28-106.87)^{+}$ \\
\hline \multicolumn{5}{|l|}{ z-score (quartiles) } \\
\hline $1(\geqslant-1.70)$ & 1 & 1 & 1 & 1 \\
\hline $2(\geqslant-2.57$ and $<-1.70)$ & NA & NA & NA & NA \\
\hline $3(\geqslant-3.17$ and $<-2.57)$ & $15.52(1.97-121.95)^{+}$ & $12.34(1.11-137.60)^{+}$ & $17.96(2.29-140.97)^{+}$ & $25.62(2.44-268.57)^{+}$ \\
\hline $4(<-3.17)$ & $9.25(1.13-75.96)^{+}$ & $6.45(0.51-81.31)$ & $8.77(1.07-72.17)^{+}$ & $16.76(1.47-190.99)^{+}$ \\
\hline \multicolumn{5}{|l|}{ (FEV $\left.1 \cdot \mathrm{Ht}^{-2}\right)_{A}$ (quartiles) } \\
\hline $1(\geqslant 0.63)$ & 1 & 1 & 1 & 1 \\
\hline $2(\geqslant 0.47$ and $<0.63)$ & $1.87(0.17-21.10)$ & 1.69 (0.12-24.38) & $1.78(0.32-10.05)$ & $1.79(0.28-11.31)$ \\
\hline $3(\geqslant 0.36$ and $<0.47)$ & $8.84(1.08-72.51)^{+}$ & $5.89(0.57-61.31)$ & $3.50(0.70-17.49)$ & $3.17(0.56-17.91)$ \\
\hline \multirow{2}{*}{\multicolumn{5}{|c|}{$\left.(F E V)_{1} \cdot \mathrm{Ht}^{-2}\right)_{B}{ }^{\natural}$}} \\
\hline & & & & \\
\hline $1(\geqslant 0.50)$ & 1 & 1 & 1 & 1 \\
\hline $2(\geqslant 0.40$ and $<0.50)$ & 3.02 (0.49-18.56) & $2.16(0.32-14.87)$ & $1.45(0.31-6.69)$ & $1.38(0.29-6.70)$ \\
\hline $3(\geqslant 0.30$ and $<0.40)$ & $12.04(2.59-56.08)^{\S}$ & $8.54(1.60-45.66)^{+}$ & $5.37(1.61-17.90)^{+}$ & $5.35(1.49-19.23)^{+}$ \\
\hline $4(<0.30)$ & $14.65(2.80-76.68)^{\S}$ & $8.41(1.29-54.94)^{+}$ & $7.57(1.98-28.95)^{\S}$ & $8.33(1.88-36.94)^{+}$ \\
\hline \multicolumn{5}{|l|}{$\mathrm{FEV} 1 \cdot \mathrm{Ht}^{-3}$ (quartiles) } \\
\hline $1(\geqslant 0.38)$ & 1 & 1 & 1 & 1 \\
\hline $2(\geqslant 0.29$ and $<0.38)$ & $3.29(0.34-32.36)$ & $3.01(0.25-37.03)$ & 2.09 (0.37-11.79) & $2.17(0.35-13.40)$ \\
\hline $3(\geqslant 0.22$ and $<0.29)$ & 7.79 (0.94-64.87) & $5.90(0.57-60.91)$ & $4.18(0.86-20.40)$ & $4.01(0.74-21.69)$ \\
\hline $4(<0.22)$ & $16.71(2.09-133.34)^{+}$ & 9.88 (0.97-100.50) & $6.43(1.33-31.06)^{+}$ & $6.29(1.15-34.42)^{+}$ \\
\hline \multicolumn{5}{|l|}{ FEV $1 Q$ (quartiles) } \\
\hline $1(\geqslant 3.38)$ & 1 & 1 & 1 & 1 \\
\hline $2(\geqslant 2.50$ and $<3.38)$ & $2.00(0.18-22.54)$ & $2.12(0.14-31.40)$ & $1.46(0.24-8.99)$ & $1.51(0.22-10.61)$ \\
\hline $3(\geqslant 1.90$ and $<2.50)$ & $8.85(1.08-72.65)^{+}$ & $6.41(0.57-72.18)$ & $3.67(0.73-18.32)$ & $3.54(0.61-20.62)$ \\
\hline $4(<1.90)$ & $12.95(1.63-103.15)^{+}$ & 7.83 (0.70-87.15) & $6.48(1.38-30.48)^{+}$ & $7.11(1.26-40.01)^{+}$ \\
\hline
\end{tabular}

FEV1: forced expiratory volume in $1 \mathrm{~s} ; \mathrm{FEV} 1 \%$ pred: percentage of predicted FEV1; GOLD: Global Initiative for Chronic Obstructive Lung Disease; $\mathrm{FEV} 1 \cdot \mathrm{Ht}^{-2}$ : $\mathrm{FEV} 1$ over height squared; $\mathrm{FEV} 1 \cdot \mathrm{Ht}^{-3}$ : $\mathrm{FEV} 1$ over height cubed; $\mathrm{FEV} 1 \mathrm{Q}$ : FEV1 quotient; $\mathrm{NA}$ : statistical estimate could not be obtained owing to too few event counts. " : adjustment was made for age, body mass index, Charlson comorbidity index, smoking status, and history of SAE in the preceding year; ${ }^{\Uparrow}$ : the cut-off values $(0.3,0.4,0.5)$ were proposed in $[7] ;{ }^{+}: p<0.05 ;{ }^{\S}: p<0.005$.

supported by the work of Pedone et al. [10]. Moreover, VAz Fragoso and co-workers [4, 5] applied z-scores of FEV1 to stage COPD among elderly patients, and found that advanced stages based on $\mathrm{z}$-scores were associated with enhanced risks of adverse outcomes and worsened respiratory symptoms. Furthermore, it is unclear whether the use of the GLI reference equations for the calculation of FEV 1 $\%$ pred and $\mathrm{z}$-scores alters the performance of these staging methods in predicting outcomes. Hegendörfer et al. [12] applied the GLI reference equations and compared staging based on five different expressions of $\mathrm{FEV}_{1}$ in predicting mortality, unplanned hospitalisation, and physical and mental decline. They also identified $\mathrm{FEV} 1 \mathrm{Q}$ and $\mathrm{FEV} 1 \cdot \mathrm{Ht}^{-3}$ as the two best methods in predicting outcomes. Nevertheless, only about $14 \%$ of the subjects in their study cohort had COPD [12]. To the best of our knowledge, our present study is the first to have applied the GLI reference equations and compared the performance of different expressions of FEV1 in staging COPD and predicting disease-specific outcomes on a cohort of patients all having COPD.

The findings of our present work agree with previous studies in that staging based on $F E V_{1} Q$ and $\left(\mathrm{FEV} \cdot \mathrm{Ht}^{-2}\right)_{\text {В }}$ performed well in predicting and stratifying the risks of adverse outcomes, in both singleand multivariate analyses. This carries practical importance, because in clinical settings clinicians often 

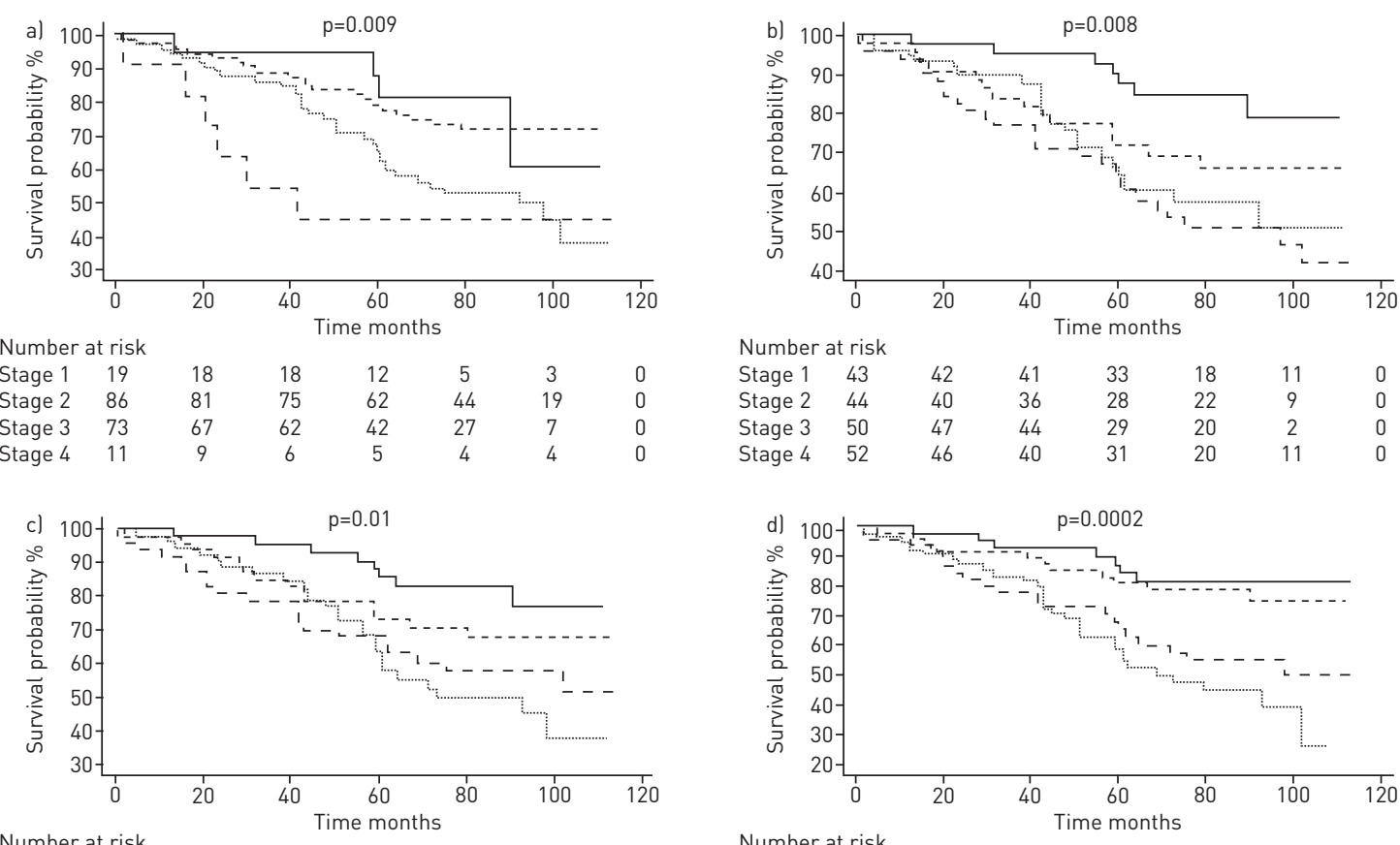

$\begin{array}{llllllll}\text { Stage 1 } & 44 & 43 & 42 & 33 & 18 & 11 & 0 \\ \text { Stage 2 } & 46 & 43 & 38 & 29 & 22 & 10 & 0 \\ \text { Stage 3 } & 52 & 48 & 44 & 30 & 19 & 2 & 0 \\ \text { Stage 4 } & 47 & 41 & 37 & 29 & 21 & 10 & 0\end{array}$

\begin{tabular}{llllllll}
\multicolumn{2}{l}{ Number at risk } & \multicolumn{7}{c}{ (30 } & 16 & 9 & 0 \\
Stage 1 & 41 & 40 & 38 & 30 & 29 & 11 & 0 \\
Stage 2 & 48 & 44 & 43 & 36 & 16 & 3 & 0 \\
Stage 3 & 55 & 50 & 45 & 29 & 16 & 10 & 0 \\
Stage 4 & 45 & 41 & 35 & 26 & 19
\end{tabular}
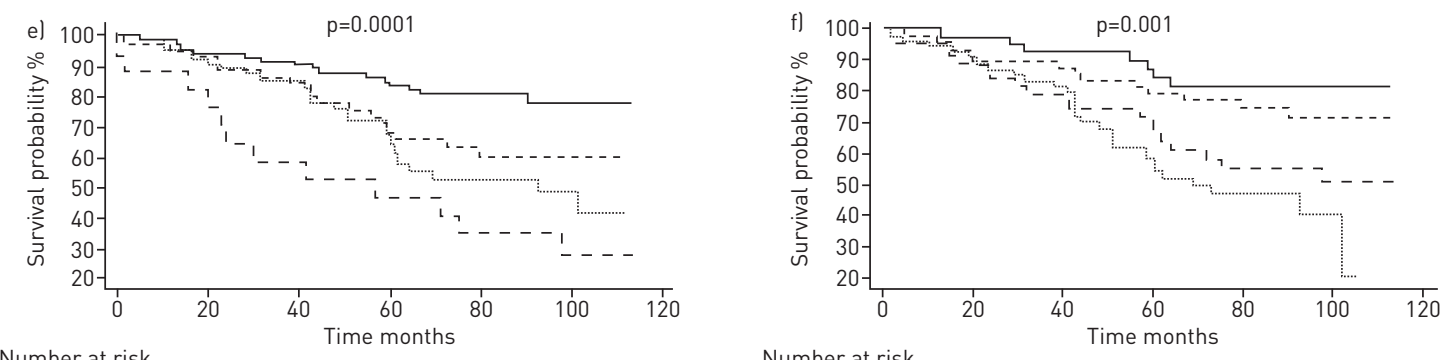

$\begin{array}{llllllll}\text { Number at risk } & & & & & \\ \text { Stage 1 } & 75 & 71 & 68 & 57 & 38 & 19 & 0 \\ \text { Stage 2 } & 46 & 43 & 39 & 28 & 18 & 3 & 0 \\ \text { Stage 3 } & 51 & 47 & 44 & 28 & 19 & 7 & 0 \\ \text { Stage 4 } & 17 & 14 & 10 & 8 & 5 & 4 & 0\end{array}$

$\begin{array}{llllllll}\text { Stage 1 } & 42 & 41 & 39 & 31 & 17 & 11 & 0 \\ \text { Stage 2 } & 49 & 44 & 43 & 36 & 29 & 10 & 0 \\ \text { Stage 3 } & 54 & 49 & 44 & 28 & 16 & 2 & 0 \\ \text { Stage 4 } & 44 & 41 & 35 & 26 & 18 & 10 & 0\end{array}$

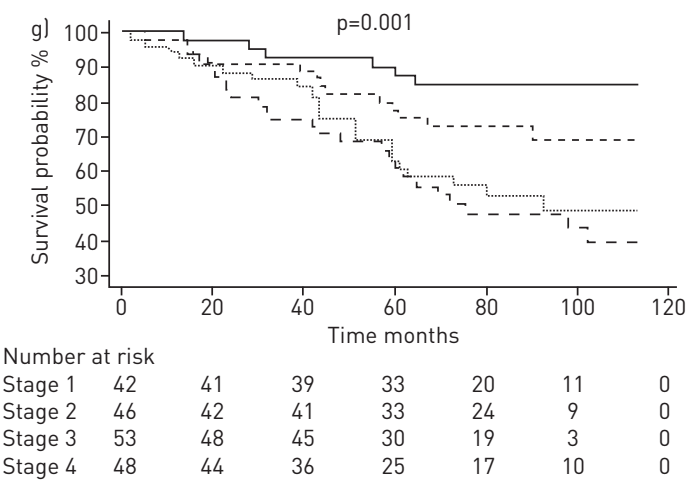

Stages
-1
---2
$-\cdots \cdots \cdots$
--4

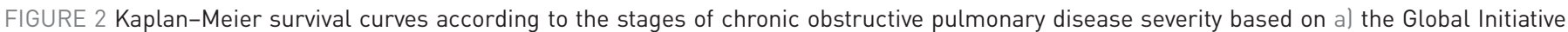
for Chronic Obstructive Lung Disease (GOLD) criteria; b) quartiles of percentage of predicted forced expiratory volume in $1 \mathrm{~s}$ (FEV $1 \%$ pred); c) quartiles of the $z$-scores of $F E V_{1}$; d) $F E V_{1}$ over height squared using quartiles as cut-off values (FEV1.Ht $\left.{ }^{-2}\right)_{A}$; e) $F E_{1}$ over height squared using the cut-off values proposed in [7] $(0.3,0.4,0.5)\left(F E V_{1} \cdot \mathrm{Ht}^{-2}\right)_{\mathrm{B}}$; f) quartiles of $\mathrm{FEV} 1$ over height cubed $\left(\mathrm{FEV} 1 \cdot \mathrm{Ht}^{-3}\right)$; and g) quartiles of $\mathrm{FEV} 1$ quotient (FEV1Q). 


\begin{tabular}{|c|c|c|}
\hline $\begin{array}{l}\text { Method of staging (cut-off } \\
\text { values) }\end{array}$ & $\begin{array}{l}\text { Crude HR for all-cause mortality } \\
\qquad(95 \% \mathrm{CI})\end{array}$ & $\begin{array}{l}\text { Adjusted } \mathrm{HR}^{\#} \text { for all-cause mortality } \\
\qquad(95 \% \mathrm{CI})\end{array}$ \\
\hline \multicolumn{3}{|l|}{ FEV $1 \%$ pred (GOLD) } \\
\hline $1(\geqslant 80 \%)$ & 1 & 1 \\
\hline $2(\geqslant 50 \%$ and $<80 \%)$ & $1.20(0.42-3.48)$ & $1.13(0.38-3.33)$ \\
\hline $3(\geqslant 30 \%$ and $<50 \%)$ & $2.50(0.89-7.04)$ & $2.00(0.69-5.78)$ \\
\hline $4(<30 \%)$ & 3.33 (0.94-11.85) & $3.81(1.03-14.07)^{+}$ \\
\hline \multicolumn{3}{|l|}{ FEV $1 \%$ pred (quartiles) } \\
\hline $1(\geqslant 69.3 \%)$ & 1 & 1 \\
\hline $2(\geqslant 53.6 \%$ and $<69.3 \%)$ & $2.15(0.87-5.34)$ & $1.97(0.79-4.95)$ \\
\hline $3(\geqslant 41.0 \%$ and $<53.6 \%)$ & $3.10(1.32-7.30)^{+}$ & $2.80(1.18-6.65)^{+}$ \\
\hline $4(<41.0 \%)$ & $3.73(1.62-8.59)^{\S}$ & $3.10(1.31-7.33)^{+}$ \\
\hline \multicolumn{3}{|l|}{ z-score (quartiles) } \\
\hline $1(\geqslant-1.70)$ & 1 & 1 \\
\hline $2(\geqslant-2.57$ and $<-1.70)$ & $1.84(0.77-4.38)$ & $1.46(0.61-3.53)$ \\
\hline $3(\geqslant-3.17$ and $<-2.57)$ & $3.31(1.49-7.31)^{\S}$ & $2.73(1.22-6.12)^{+}$ \\
\hline $4(<-3.17)$ & $2.76(1.21-6.26)^{+}$ & $3.48(1.43-8.46)^{+}$ \\
\hline \multicolumn{3}{|l|}{$\left(\mathrm{FEV} 1 \cdot \mathrm{Ht}^{-2}\right)_{\mathrm{A}}$ (quartiles) } \\
\hline $1(\geqslant 0.63)$ & 1 & 1 \\
\hline $2(\geqslant 0.47$ and $<0.63)$ & $1.31(0.51-3.38)$ & $0.94(0.36-2.50)$ \\
\hline $3(\geqslant 0.36$ and $<0.47)$ & $4.08(1.79-9.30)^{\S}$ & $2.65(1.13-6.20)^{+}$ \\
\hline $4(<0.36)$ & $3.00(1.27-7.09)^{+}$ & $2.02(0.83-4.92)$ \\
\hline \multicolumn{3}{|l|}{$\left(\mathrm{FEV} 1 \cdot \mathrm{Ht}^{-2}\right)_{\mathrm{B}}{ }^{\Upsilon}$} \\
\hline $1(\geqslant 0.50)$ & 1 & 1 \\
\hline $2(\geqslant 0.40$ and $<0.50)$ & $2.16(1.08-4.34)^{+}$ & $2.00(0.99-4.06)$ \\
\hline $3(\geqslant 0.30$ and $<0.40)$ & $2.83(1.48-5.41)^{\S}$ & $2.00(1.02-3.94)^{+}$ \\
\hline $4(<0.30)$ & $4.95(2.31-10.58)^{\S}$ & $4.78(2.17-10.54)^{\S}$ \\
\hline \multicolumn{3}{|l|}{$\mathrm{FEV} 1 \cdot \mathrm{Ht}^{-3}$ (quartiles) } \\
\hline $1(\geqslant 0.38)$ & 1 & 1 \\
\hline $2(\geqslant 0.29$ and $<0.38)$ & $1.60(0.64-4.02)$ & $1.14(0.45-2.92)$ \\
\hline $3(\geqslant 0.22$ and $<0.29)$ & $4.20(1.83-9.60)^{\S}$ & $2.78(1.20-6.47)^{+}$ \\
\hline $4(<0.22)$ & $2.99(1.25-7.10)^{+}$ & $1.90(0.77-4.65)$ \\
\hline \multicolumn{3}{|l|}{ FEV1Q (quartiles) } \\
\hline $1(\geqslant 3.38)$ & 1 & 1 \\
\hline $2(\geqslant 2.50$ and $<3.38)$ & $2.11(0.80-5.56)$ & $1.39(0.51-3.80)$ \\
\hline $3(\geqslant 1.90$ and $<2.50)$ & $3.98(1.62-9.74)^{\S}$ & $2.56(1.02-6.46)^{+}$ \\
\hline $4(<1.90)$ & $4.62(1.89-11.27)^{\S}$ & $2.80(1.10-7.15)^{+}$ \\
\hline
\end{tabular}

HR: hazard ratio; FEV1: forced expiratory volume in $1 \mathrm{~s} ; \mathrm{FEV} 1 \%$ pred: percentage of predicted FEV1; GOLD: Global Initiative for Chronic Obstructive Lung Disease; FEV1. $\mathrm{Ht}^{-2}$ : $\mathrm{FEV} 1$ over height squared; $\mathrm{FEV}_{1} \cdot \mathrm{Ht}^{-3}$ : FEV1 over height cubed; FEV1Q: FEV1 quotient. "\#: adjustment was made for age, body mass index, Charlson comorbidity index, smoking status, and history of serious adverse event in the preceding year; ${ }^{\text {? }}$ : the cut-off values $(0.3,0.4,0.5)$ were proposed in $[7] ;^{+}: p<0.05 ;{ }^{\S}: p<0.005$.

weigh those patient-specific variates differentially and even consider the severity stages in isolation. Like previous researchers, we also found that the widely applied GOLD criteria performed inadequately in predicting outcomes, particularly the risk of SAE. The GOLD criteria and $\left(\mathrm{FEV}_{1} \cdot \mathrm{Ht}^{-2}\right)_{\mathrm{B}}$ both used cut-off values that resulted in an uneven splitting of the patients. Consistent with the findings of Miller et al. [7], compared with the GOLD criteria, $\left(\mathrm{FEV} 1 \cdot \mathrm{Ht}^{-2}\right)_{\mathrm{B}}$ classified more patients into the highest and lowest stages than into intermediate stages 2 and 3, and yet it performed better than the GOLD criteria in predicting outcomes. Our present study differs from those of VAZ FRAGOSO and co-workers $[4,5]$ in that we did not observe any advantage in terms of outcome prediction in z-score-based staging. The performance of $\mathrm{Z}$-scores in outcome prediction was still unsatisfactory following the use of the five-stage cut-off values proposed by QUANJER et al. [6] (table S3 and figure S2a). Unlike in previous studies, the performance of staging based on $\mathrm{FEV} 1 \cdot \mathrm{Ht}^{-3}$ in the present study was inadequate in discriminating the differences in survival and mortality risk, and this could not be improved by changing the cut-off values to quintiles as proposed by PEDone et al. [10] (table S3 and figure S2b). When we analysed the risks of having at least one SAE at 2 and 3 years of follow-up, FEV1Q-based staging was the only method that consistently yielded a stepwise increase in all the crude and adjusted odds ratios with advancing stages (table S4). 
Another important implication from our findings is that the performance of staging methods in predicting outcomes can also be influenced by the choice of cut-off values. This was demonstrated by the difference in performance between the GOLD criteria and $\mathrm{FEV}_{1} \%$ pred (quartiles), and also between $\left(\mathrm{FEV} 1 \cdot \mathrm{Ht}^{-2}\right)_{\mathrm{A}}$ and $\left(\mathrm{FEV} \cdot \mathrm{Ht}^{-2}\right)_{\mathrm{B}}$. It is unlikely that the relationship between the severity of COPD based on any staging method and the risk of various adverse outcomes is linear. The best cut-off values, even for staging with FEV1Q, may still need to be refined and validated, particularly in large clinical populations.

There are some limitations to the present study. First, the relatively small size of our cohort might have rendered our study insensitive to subtle differences. Nevertheless, the application of bootstrapping helped to offset this limitation. Second, the majority of our participants were male, which was mainly because of the epidemiology of cigarette smoking and COPD in Taiwan, where more than 95\% of smokers are male [35]. Generalising our findings to populations with different sex ratios needs to be carried out with caution. Third, this study was conducted in the outpatient setting of a single tertiary medical centre, and the conclusions might not be generalisable to all patients with COPD. Finally, we did not analyse psychosocial factors or treatments in our participants, and therefore cannot exclude the potential confounding effects from those factors.

\section{Conclusion}

We show that staging of COPD severity based on the GOLD criteria performed inadequately in predicting the risk of adverse outcomes. Staging based on the reference-independent FEV1Q using quartiles as cut-off values best predicted the risks of SAE and mortality and performed well in stratifying the differences in survival. Staging based on $\left(\mathrm{FEV} 1 \cdot \mathrm{Ht}^{-2}\right)_{\mathrm{B}}$ was the next best performing method. The performance of staging methods depends on the expression of FEV1 and on the choice of cut-off values.

Acknowledgements: We thank all the patients enrolled in this study for their contribution. We are also grateful to Wei-Ming Wang, Wan-Ni Chen and Chih-Hui Hsu, statisticians from the Biostatistics Consulting Center of National Cheng Kung University Hospital, for providing statistical consultation and assistance. Parts of the data in this paper were presented in a poster discussion entitled "In- and out-patient COPD management" at the European Respiratory Society 2016 International Congress.

Author contributions: T-H. Huang: study design, acquisition of subjects, data analysis and interpretation, figures and tables, writing of manuscript. T-R. Hsiue, P-L. Su, X-M. Liao: acquisition of subjects, data analysis, and comments on data interpretation and figures. S-H. Lin: consultation and assistance on statistical analysis, computation, and interpretation. C-Z. Chen: study design and concept, analysis and interpretation of data, writing of manuscript.

\section{References}

1 Global Initiative for Chronic Obstructive Lung Disease (GOLD). Global Strategy for the Diagnosis, Management and Prevention of COPD 2017. Available from: http://goldcopd.org/

2 Quanjer PH, Enright PL, Miller MR, et al. The need to change the method for defining mild airway obstruction. Eur Respir J 2011; 37: 720-722.

3 Quanjer PH, Stanojevic S, Cole TJ, et al. Multi-ethnic reference values for spirometry for the 3-95 year age range: the Global Lung Function 2012 equations. Eur Respir J 2012; 40: 1324-1343.

4 Vaz Fragoso CA, Concato J, McAvay G, et al. Staging the severity of chronic obstructive pulmonary disease in older persons based on spirometric z-scores. J Am Geriatr Soc 2011; 59: 1847-1854.

5 Vaz Fragoso CA, Concato J, McAvay G, et al. Respiratory impairment and COPD hospitalisation in older persons: a competing risk analysis. Eur Respir J 2012; 40: 37-44.

6 Quanjer PH, Pretto JJ, Brazzale DJ, et al. Grading the severity of airways obstruction: new wine in new bottles. Eur Respir J 2014; 43: 505-512.

7 Miller MR, Pedersen OF, Dirksen A. A new staging strategy for chronic obstructive pulmonary disease. Int J Chron Obstruct Pulmon Dis 2007; 2: 657-663.

8 Miller MR, Pedersen OF, Lange $\mathrm{P}$, et al. Improved survival prediction from lung function data in a large population sample. Respir Med 2009; 103: 442-448.

9 Miller MR, Pedersen OF. New concepts for expressing forced expiratory volume in $1 \mathrm{~s}$ arising from survival analysis. Eur Respir J 2010; 35: 873-882.

10 Pedone C, Scarlata S, Scichilone N, et al. Alternative ways of expressing FEV $_{1}$ and mortality in elderly people with and without COPD. Eur Respir J 2013; 41: 800-805.

11 Turkeshi E, Vaes B, Andreeva E, et al. Short-term prognostic value of forced expiratory volume in 1 second divided by height cubed in a prospective cohort of people 80 years and older. BMC Geriatrics 2015; 15: 15 .

12 Hegendörfer E, Vaes B, Andreeva E, et al. Predictive value of different expressions of forced expiratory volume in 1 second (FEV1) for adverse outcomes in a cohort of adults aged 80 and older. J Am Med Dir Assoc 2017; 18: $123-130$

13 Chen CZ, Ou CY, Wang WL, et al. Using post-bronchodilator FEV1 is better than pre-bronchodilator FEV1 in evaluation of COPD severity. COPD 2012; 9: 1-5.

14 Vollmer WM, Gíslason p, Burney P, et al. Comparison of spirometry criteria for the diagnosis of COPD: results from the BOLD study. Eur Respir J 2009; 34: 588-597.

15 van Dijk W, Tan W, Li P, et al. Clinical relevance of fixed ratio vs lower limit of normal of $\mathrm{FEV}_{1} / \mathrm{FVC}$ in COPD: patient-reported outcomes from the CanCOLD Cohort. Ann Fam Med 2015; 13: 41-48. 
16 Criner GJ, Bourbeau J, Diekemper RL, et al. Prevention of acute exacerbation of COPD: American College of Chest Physicians and Canadian Thoracic Society Guideline. Chest 2015; 147: 883-893.

17 Blonshine S, Mottram CD, Wanger J. Pulmonary Function Laboratory Management and Procedure Manual. 2nd Edn. New York, American Thoracic Society, 2005.

18 Garcia-Aymerich J, Farrero E, Félez MA, et al. Risk factors of readmission to hospital for a COPD exacerbation: a prospective study. Thorax 2003; 58: 100-105.

19 Ong KC, Earnest A, Lu SJ. A multidimensional grading system (BODE Index) as predictor of hospitalization for COPD. Chest 2005; 128: 3810-3816.

20 Bahadori K, FitzGerald JM. Risk factors of hospitalization and readmission of patients with COPD exacerbation systematic review. Int J Chron Obstruct Pulmon Dis 2007; 2: 241-251.

21 Hurst JR, Vestbo J, Anzueto A, et al. Susceptibility to exacerbation in chronic obstructive pulmonary disease. N Engl J Med 2010; 363: 1128-1138.

22 Bertens LCM, Reitsma JB, Moons KGM, et al. Development and validation of a model to predict the risk of exacerbations in chronic obstructive pulmonary disease. Int J Chron Obstruct Pulmon Dis 2013; 8: 493-499.

23 Müllerová $\mathrm{H}$, Shukla A, Hawkins A, et al. Risk factors for acute exacerbations of COPD in a primary care population: a retrospective observational cohort study. BMJ Open 2014; 4: e006171.

24 Kerkhof M, Freeman D, Jones R, et al. Predicting frequent COPD exacerbations using primary care data. Int J Chron Obstruct Pulmon Dis 2015; 10: 2439-2450.

25 Montserrat-Capdevila J, Godoy P, Marsal JR, et al. Risk factors for exacerbation in chronic obstructive pulmonary disease: a prospective study. Int J Tuberc Lung Dis 2016; 20: 389-395.

26 Pavord ID, Jones PW, Burgel PR, et al. Exacerbations of COPD. Int J Chron Obstruct Pulmon Dis 2016; 11: 21-30.

27 Ko FW, Chan KP, Hui DS, et al. Acute exacerbation of COPD. Respirology 2016; 21: 1152-1165.

28 Traver GA, Cline MG, Burrows B. Predictors of mortality in chronic obstructive pulmonary disease: a 15-year follow-up study. Am Rev Respir Dis 1979; 119: 895-902.

29 Anthonisen NR, Wright EC, Hodgkin JE, et al. Prognosis in chronic obstructive pulmonary disease. Am Rev Respir Dis 1986; 133: 14-20.

30 Celli BR, Cote CG, Marin JM, et al. The body-mass index, airflow obstruction, dyspnea, and exercise capacity index in chronic obstructive pulmonary disease. N Engl J Med 2004; 350: 1005-1012.

31 Ekberg-Aronsson M, Pehrsson K, Nilsson JA, et al. Mortality in GOLD stages of COPD and its dependence on symptoms of chronic bronchitis. Respir Res 2005; 6: 98

32 Gunen H, Hacievliyagil SS, Kosar F, et al. Factors affecting survival of hospitalised patients with COPD. Eur Respir J 2005; 26: 234-241.

33 Martinez FJ, Foster G, Curtis JL, et al. Predictors of mortality in patients with emphysema and severe airflow obstruction. Am J Respir Crit Care Med 2006; 173: 1326-1334.

34 Martinez FJ, Han MK, Andrei AC, et al. Longitudinal change in the BODE index predicts mortality in severe emphysema. Am J Respir Crit Care Med 2008; 178: 491-499.

35 Jamrozik E, Musk AW. Respiratory health issues in the Asia-Pacific region: an overview. Respirology 2011; 16: $3-12$. 